\title{
DNA-Programmed Chemical Synthesis of Polymers and Inorganic Nanomaterials
}

\author{
Xuemei $\mathrm{Xu}^{1} \cdot$ Pia Winterwerber ${ }^{2} \cdot$ David $\mathrm{Ng}^{2} \cdot$ Yuzhou $\mathrm{Wu}^{1,2}$ (D)
}

Received: 30 October 2019 / Accepted: 17 February 2020 / Published online: 7 March 2020

(c) The Author(s) 2020

\begin{abstract}
DNA nanotechnology, based on sequence-specific DNA recognition, could allow programmed self-assembly of sophisticated nanostructures with molecular precision. Extension of this technique to the preparation of broader types of nanomaterials would significantly improve nanofabrication technique to lower nanometer scale and even achieve single molecule operation. Using such exquisite DNA nanostructures as templates, chemical synthesis of polymer and inorganic nanomaterials could also be programmed with unprecedented accuracy and flexibility. This review summarizes recent advances in the synthesis and assembly of polymer and inorganic nanomaterials using DNA nanostructures as templates, and discusses the current challenges and future outlook of DNA templated nanotechnology.
\end{abstract}

Keywords DNA origami · Polymer nanomaterial · Inorganic nanomaterial · Programmed synthesis · Bottom-up nanofabrication

\section{Introduction}

DNA, often known as the genetic code, exists in natural organisms. In 1953, the double helix structure of DNA was discovered, which revealed the mystery of life and enabled people to understand clearly the composition and transmission of genetic information [1]. Two reversely parallel complementary DNA single strands can recognize each other via Watson-Crick base pairing, forming a stable DNA

Chapter 3 was originally published as Xu, X., Winterwerber, P., Ng, D. \& Wu, Y. Topics in Current Chemistry (2020) 378: 31. https://doi.org/10.1007/s41061-020-0292-X.

Yuzhou Wu

wuyuzhou@hust.edu.cn

1 Hubei Key Laboratory of Bioinorganic Chemistry and Materia Medica, School of Chemistry and Chemical Engineering, Huazhong University of Science and Technology, Luoyu Road 1037, Hongshan, Wuhan 430074, People's Republic of China

2 Max Planck Institute for Polymer Research, Ackermannweg 10, 55128 Mainz, Germany 
double helix with high accuracy from sequence to structure [2]. In the process of life activities, the double helix structure can be dissociated and hybridized dynamically during transcription, replication or repair, which provides a vital guarantee for the recording, transmission and translation of genetic information [3].

In recent decades, enthusiasm for DNA molecules has expanded from the initial biological and chemical arena to that of nanomaterials. Given the advantages of accuracy and design flexibility, advances in DNA self-assembly techniques [4] have made DNA structures a new type of "star" material in nanotechnology. DNA nanotechnology was pioneered by Seeman and co-workers in the 1980s [5-8], and has been revolutionized by Rothemund into a state-of-the-art technology, i.e., DNA origami [9]. This technology allows folding of DNA nanostructures by mixing and annealing a long single circular DNA scaffold with hundreds of short "staple" strands. In practice, this enables the construction of almost any kind of highly complex two-dimensional (2D) and three-dimensional (3D) nanostructure with the aid of computing software such as caDNAno [10-15]. To address the cost limitations of DNA material, Dietz has devised a biotechnological mass production method, which provides impetus for the practical application of DNA origami in the future [16].

Intriguingly, the glamour of life is that DNA is not only capable of storing genetic information, but can also precisely translate this information into another materialprotein. The sequence-dependent hybridization mechanism ensures that DNA can stably store genetic information and its heredity. In its natural state, DNA provides limited structural features and functional diversity. Therefore, DNA does not directly serve as a functional material, but instead, its sequence-encoded information is transcribed and expanded into the sequence of protein, and, in this way, renders diversity in life. Such an elegant strategy has also inspired material chemists. If DNA nanotechnology could be expanded to prepare diverse materials, the programmable features of DNA nanostructures might endow them with exquisite and unlimited physical and chemical properties, thus bringing a potential revolution to nanomaterial science. Encouraged by this vision, the use of DNA nanostructures as templates to control the precise synthesis of organic and inorganic materials has attracted increasing attention in recent years. In this review, we discuss the latest progress in the field of DNA-programmed material science, with a focus on the synthesis of polymer and inorganic materials employing DNA nanostructures as templates in order to achieve unprecedented accuracy at the nano scale (Fig. 1).

\section{DNA-Sequence-Encoded Polymer Synthesis}

As the most important storage material of natural genetic information, DNA can encode the synthesis of proteins in natural organisms and, accordingly, determine all of life's activities. The ability to synthesize protein macromolecules using nucleic acids as templates enables proteins to evolve into complex structures and functions with remarkable specificity and reliability. In contrast, traditional chemical polymerization reactions cannot precisely control the sequence of monomers, or their molecular weight distribution. Therefore, synthetic polymers typically could not display defined structures and functions as proteins [17-19]. Despite great progress 


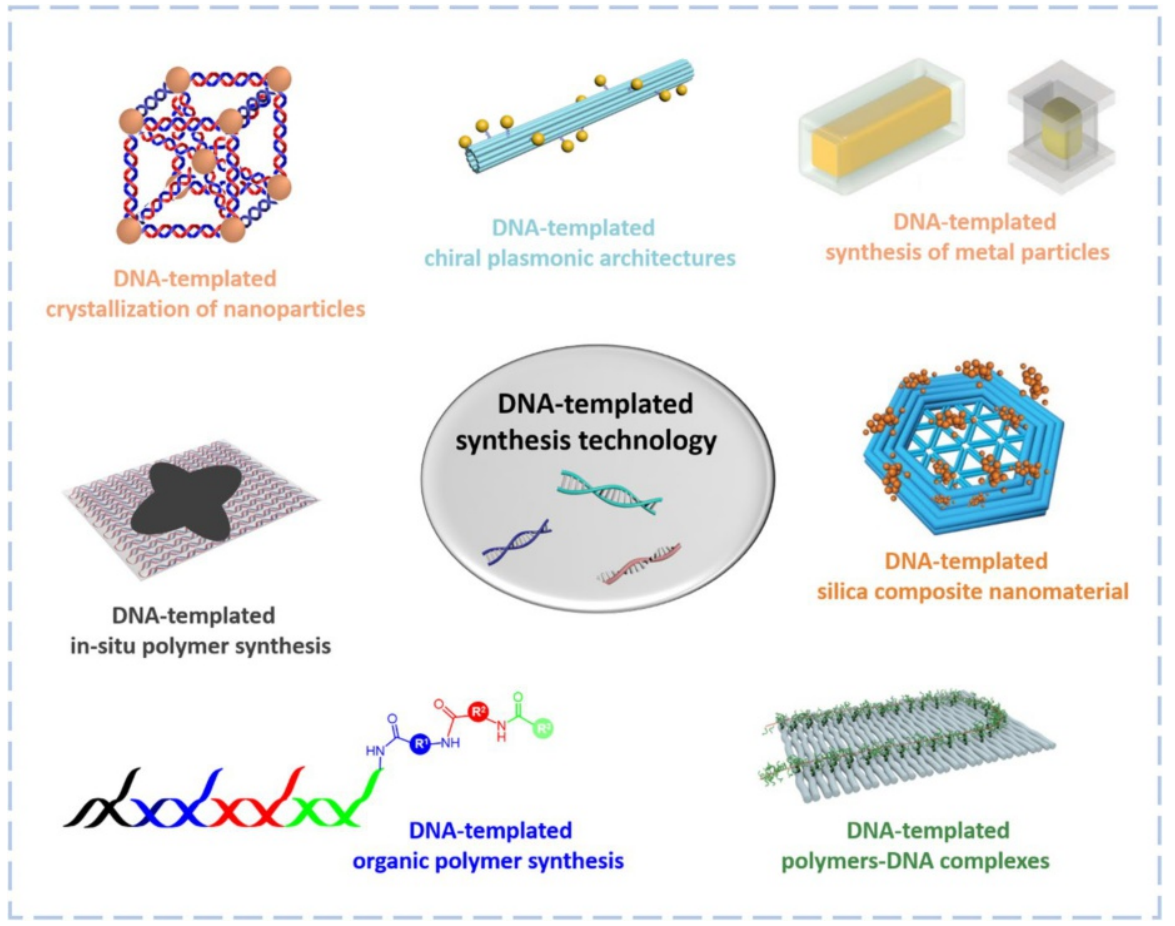

Fig. 1 DNA-templated synthetic technology

in controlling the structure $[20,21]$ and molecular weight distribution $[22,23]$ of synthetic polymers, it is still difficult to precisely control their sequence and length. However, it has been possible to achieve controlled polymer molecules by taking advantage of DNA sequences to guide the polymerization process. The technology of DNA-encoded polymer synthesis is devoted to more accurate design and preparation of polymer materials, and more precise control of their structure and function $[24,25]$.

Inspired by the DNA transcription process, Hollige et al. [26, 27] designed a DNA polymerase that allows enzymatic synthesis of nucleic acid analogs with non-natural polymer backbone and DNA hybridizing side chains, such as arabino nucleic acid (ANA) and 2'-fluoro-arabino-nucleic acid (FANA), locked nucleic acids (LNA), threose nucleic acid (TNA), hexonucleic acid (HNA), and cyclohexyl nucleic acid (CeNA) (Fig. 2). These DNA analogs are so-called XNAs. This study demonstrated for the first time that genetic information can be stored in, and recovered from, synthetic genetic polymers not found in nature. They have also shown that some XNAs could be replicated and folded into complex structures. In addition, Chaput and co-workers [28] obtained a thrombin-bound TNA adapter with high affinity and specificity from TNA libraries translated by enzyme-mediated primer extension, demonstrating that TNA has the ability to fold into tertiary structures with sophisticated chemical functions. The enzymatic DNA templating synthesis of synthetic polymer backbone showed therein suggest the potential to obtain synthetic 


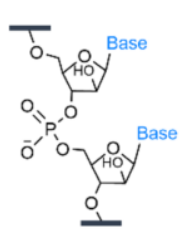

ANA

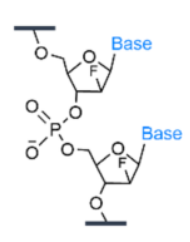

FANA

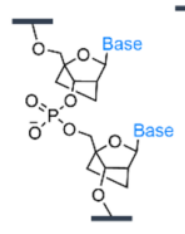

LNA

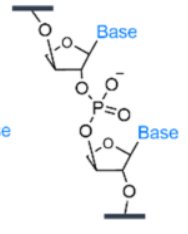

TNA

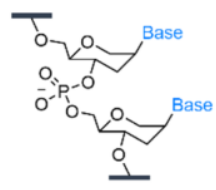

HNA

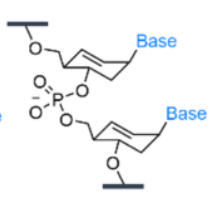

CeNA

Fig. 2 DNA analogs with non-natural backbones that could be enzymatically synthesized based on DNA template

polymers also capable of storing sequence information. However, the type of polymer backbone is highly limited.

Liu and other researchers also attempted to mimic the principle of the natural gene translation process to achieve chemical synthesis of sequence-controlled polymers based on DNA templates [29-31]. They reported the efficient and sequencespecific polymerization of non-functional [32] and side-chain-functionalized peptide nucleic acid aldehydes [33] with DNA sequence templates, combined with an in vitro translation, functional screening and amplification system [34]. Although these studies showed the potential for chemically mimicking the gene translation process, they are still limited to nucleic acid analogs. Taking a step further, more flexible synthetic monomers could be sequence specifically aligned along the DNA template by conjugating the monomers with short DNA sequences. For instance, Schuster et al. [35] used cyclic and linear DNA structures as template and DNA conjugated 2,5-bis(2-thienyl)pyrrole as monomers to achieve controlled synthesis of highly defined conducting polymers. In addition, Liu's group devoted intensive effort to study sequentially multistep reactions in a single solution using DNA templates [29-31]. Their early strategy allow DNA-tagged synthetic monomers to sequentially hybridize on a predefined DNA single-strand template, thus initiating spontaneous proximity-driven cascade reactions to connect the monomers into sequence-specific oligomers [36]. Similarly, Turberfield's group [37] used short single-strand DNA adapters to hybridize two DNA-tagged monomers, thus controlling the reaction sequence, which can also allow orthogonal synthesis of several predefined oligomers in one vessel. Nevertheless, these designs depend highly on the close distance between the assembled monomers to initiate sequential reactions, thus limiting the choice of monomers to very small moieties and hindering reaction efficiency. Thereafter, they further devised an automatic DNA walker that allows programmable multistep organic reactions that better mimic the natural DNAencoded protein synthesis process. Different monomers were encoded by specific DNA sequences so that they could be hybridized on DNA templates at predefined positions. The DNA walker could then sequentially create an amide bond between these monomers, just like a ribosome forming an ordered polypeptide chain (Fig. 3a) [38]. This strategy can potentially be applied to more diverse type of reactions, and significantly improve synthesis efficiency, particularly for longer sequences. Furthermore, these latter authors mimicked the process of transcription and translation 
(a)
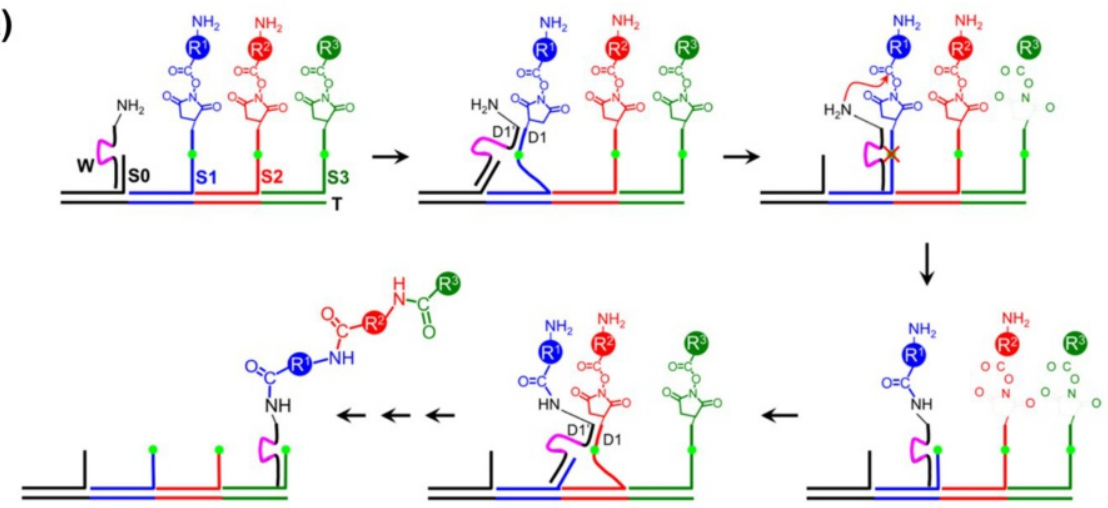

(b)

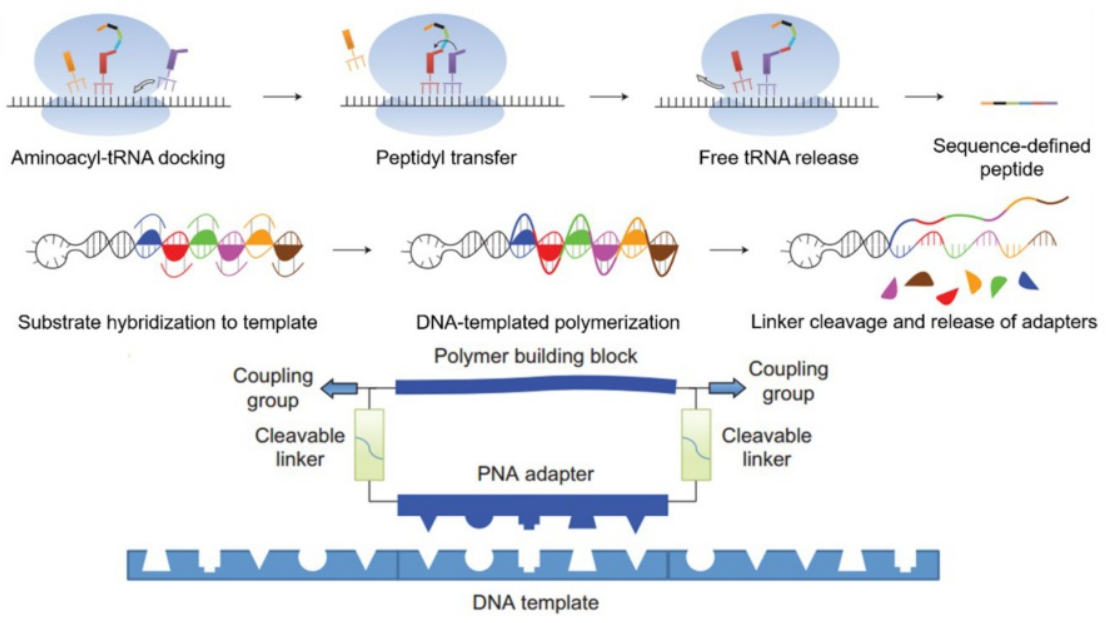

Fig. 3a,b Synthesis of polymers based on DNA templates. a DNAsome-mediated multistep synthesis of a triamide product. Reproduced with permission from Ref. [38]. Copyright 2010 Nature Publishing Group. b Synthesis of polymers with higher molecular weight arising from the process of translation from DNA into proteins. Reproduced with permission from Ref. [39]. Copyright 2013 Nature Publishing Group

of DNA into proteins in living systems, producing sequence-specific synthetic polymers with higher molecular weight; the structures of these polymers were independent of the DNA templates (Fig. 3b) [39]. These studies clearly exhibited the great potential of sequence-defined polymer synthesis using DNA templates. With this technique, polymers could be anticipated to possess more rationally designed functions and self-assembly behaviors, rather like biomacromolecules. The possibility of synthesizing sequence-defined polymers with diverse functional monomers might open up numerous new opportunities for polymer chemistry, such as precisely controlling dynamic macromolecular recognition, manipulation of sophisticated polymer assembly and creation of smart polymer nano-robots. However, as the aforementioned methods are somewhat tedious and expensive, they serve mainly as 
a proof-of-concept studies with still limited applications. Therefore, more efficient and facile methods are still required to promote the practical application of DNAtemplated polymer synthesis.

\section{Synthesis of Polymer Nanomaterials Templated by DNA Nanostructures}

As an extension of synthetic polymers encoded by simple DNA strands, in recent years, DNA nanostructures with $2 \mathrm{D}$ and $3 \mathrm{D}$ spatial conformation have also been used as templates for the synthesis of polymer nanomaterials. At present, there are two major objectives for these studies. On the one hand, researchers aim to improve the physical and chemical properties of DNA nanomaterials by polymer modification. Since DNA-folded "nano-robots" have been proposed as ideal intelligent drug carriers at the nanometer scale [40], there have been intensive studies to enhance the stability of DNA nano-robots under various practical application conditions, and to tune their physical and chemical properties by polymer modification. On the other hand, DNA nanostructures can also serve simply as templates to control polymer synthesis and assembly, providing more powerful nanofabrication techniques to achieve exquisite polymer nanostructures.

\subsection{Polymer Modified DNA Nanomaterials}

Various types of substances have been used to encapsulate DNA nanostructures to improve their physical and chemical stability. For instance, by immobilizing lipidmodified DNA on the nanostructure surface, liposome can be formed around the DNA nanostructure to enhance cell uptake efficiency (Fig. 4a) [41]. However, this method requires pre-modification of the DNA nanostructure, and it is tricky to avoid competitive micellar formation by amphiphilic DNA-lipid conjugates. Thereafter, Kostiainen and co-workers studied a series of positively charged materials designed to wrap the negatively charged DNA nanostructures via simple electrostatic interactions. In this regard, the naturally positively charged cowpea chlorotic mottle virus capsid protein was first tested and found to be beneficial to increase the efficiency of DNA nanostructures entering cancer cells (Fig. 4b) [42]. In addition, they also designed synthetic polymer conjugates with a positively charged block to interact with DNA and an uncharged hydrophilic block to facilitate aqueous stability and biocompatibility. They showed that both the positively charged PDMAEMA-PEG copolymer and the dendron-conjugated bovine serum albumin (BSA) could provide the expected functions for encapsulating brick-shaped DNA nanostructures [43, 44]. The protected DNA nanostructures exhibited complete resistance to DNase degradation, and their cell uptake efficiency was significantly enhanced by more than 2.5 times [44]. These outcomes were consistent with reports from others. For instance, Schmidt and co-workers [45] showed that polyethylene glycol and polylysine copolymers (PEG-PLys) can protect the structure of DNA against DNase I degradation and improve stability in low ionic strength buffer. Shih's group also reported that 
(a)

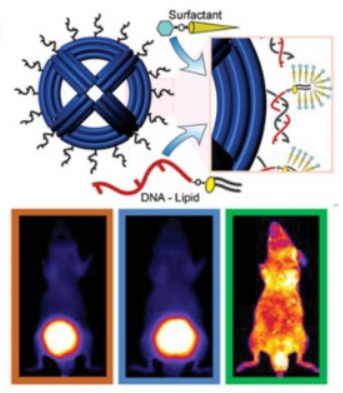

(b)

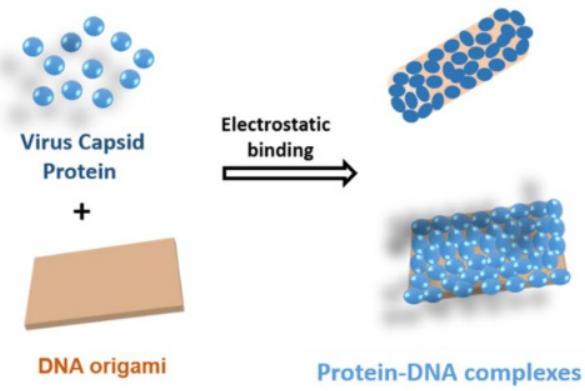

(c)
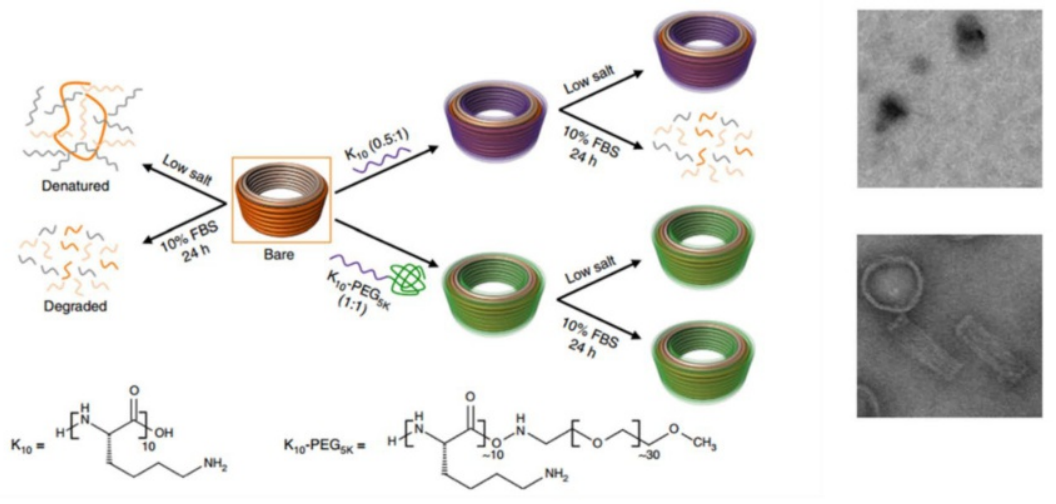

(d)

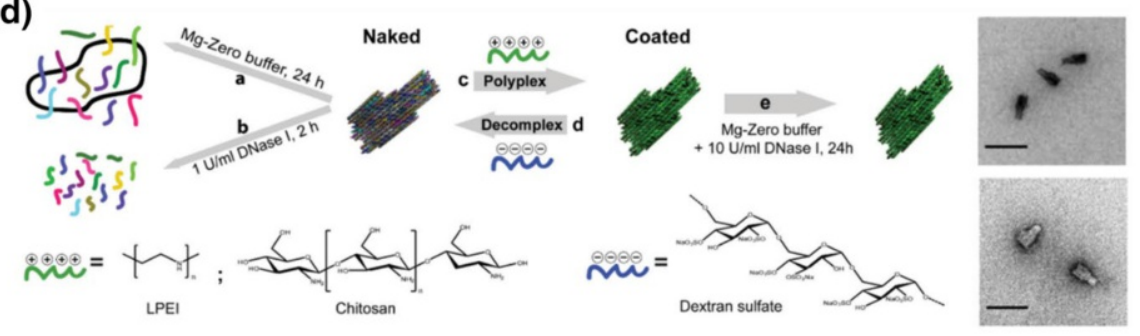

Fig. 4a-d Biopolymers interacting with DNA nanostructures. a Liposome membrane encapsulation of DNA nanostructures. Reproduced with permission from Ref. [41]. Copyright 2014 American Chemical Society. b Positively charged cowpea chlorotic mottle virus capsid protein encapsulated square DNA origami. Reproduced with permission from Ref. [42]. Copyright 2014 American Chemical Society. c Electrostatic adsorption between synthetic polymer and DNA nanostructure template. Reproduced with permission from Ref. [46]. Copyright 2017 Nature Publishing Group. d Reversible assembly of synthetic and natural cationic polymers with DNA nanostructures. Reproduced with permission from Ref. [47] Copyright 2018 Royal Society of Chemistry

PEG-PLys copolymers with different molecular weights have dissimilar impacts on the stability of DNA origami [46]. These conjugates confer $>1000$-fold increased stability against digestion by serum nucleases. Particularly, PEG-PLys copolymerencapsulated DNA nanostructures can survive uptake into endosomal compartments and, in a mouse model, exhibit a modest increase in pharmacokinetic bioavailability (Fig. 4c). Similarly, Barišić and co-workers reported that the cationic polysaccharide 
chitosan and synthetic linear polyethyleneimine (LPEI) can also protect the structural integrity of DNA origami (Fig. 4d) [47]. A similar effect was observed when using a chemically modified protein — cationic human serum albumin (HSA) — that is more biocompatible and easily available [48]. These investigations clearly demonstrated that decoration of DNA nanostructures with cationic polymers could be an efficient way to improve their physiological stability and modulate their in vitro and in vivo distribution. In this way, DNA nanostructures can better serve as smart drug delivery carriers for broader biomedical applications. However, it is noteworthy that some essential features of DNA nanostructures, such as their precisely positioned surface functionalities, DNA-sequence-dependent molecular recognition, and the intelligent mobility of specially design DNA robots, were lost during this encapsulation process. Therefore, future studies are expected to pay more attention to controlled polymer modification of DNA nanostructures at only specific positions to enhance their stability and biocompatibility while maintaining functionality. Some methods presented in the following section on Bottom-up Fabrication of Polymer Materials might provide such opportunity, but their potential in this aspect has not yet been fully explored.

\subsection{Bottom-up Fabrication of Polymer Materials}

Apart from their attractive properties and as yet not fully exploited potential as drug carriers, a role for DNA origami nanostructures as templates to control the growth of polymer nanomaterials has also been envisioned. Conventional synthetic polymerization reactions in liquid phase normally result in randomly entangled polymer chains. In contrast, by combining traditional polymer synthesis methods with DNA strands or nanostructures based on site-specific modification strategy, pre-designed polymer nanomaterials were successfully obtained. This could be achieved by in situ atom transfer radical polymerization (ATRP) polymerization on DNA chains-a technique established by Matyjaszewski and coworkers [49]. By modifying a DNA strand with a ATRP initiator, polymers can grow directly from the 5'-terminus of a DNA chain [49]. Based on this method, Weil and $\mathrm{Wu}$ and colleagues [50] achieved the synthesis of polymer nanomaterials with unique shape and patterns by prepositioning of initiators on a rectangular DNA origami tile. In this regard, the DNA tile can be considered as a "screen" with around 200 sequence-encoded "pixels". A single-strand sticky end was placed at the "pixel" that was desired to grow polymer later on. Thus, ATRP-initiator-modified DNA sequences could be hybridized on the sticky ends, thereby allowing an in situ polymerization reaction from the immobilized initiators (Fig. 5a). In this way, polymers with a designed nanopattern could be synthesized precisely. Moreover, polymer nanostructures could be released from the DNA template simply by heat-induced disassembly of the DNA tile. Compared with traditional lithography and self-assembly-based polymer nanomaterial preparation techniques, this method features high precision (up to a few nanometers) and efficiency (one-pot reaction in solution), and brings new opportunities in the synthesis of polymer nanomaterials. On the basis of this work, Weil and Wu and coworkers extended this in situ polymerzation method from 2D DNA origami to its 3D 
(a)

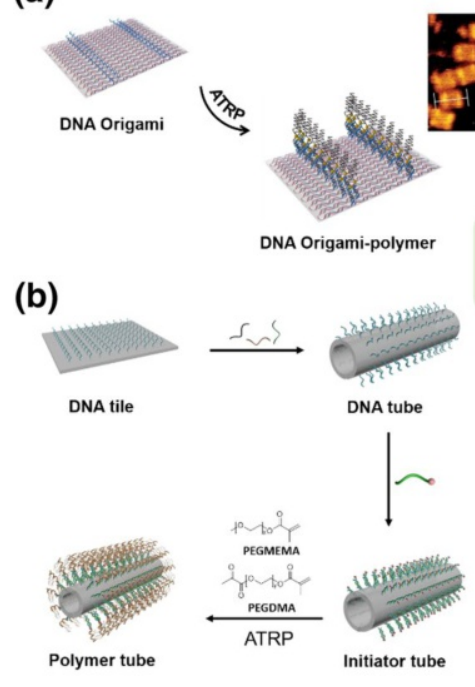

(c)

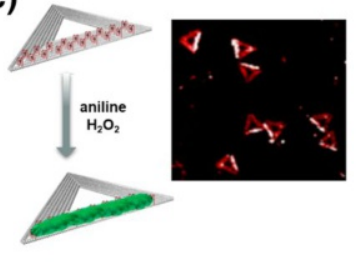

(d)

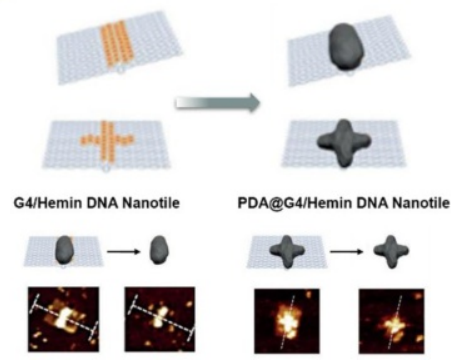

Fig. 5a-d In situ synthesis of DNA nanostructure templated polymers. a Bottom-up fabrication of polymers on DNA origami template by in situ atom transfer radical polymerization (ATRP). Reproduced with permission from Ref. [50]. Copyright 2016 Wiley-VCH. b Polymeric shell on DNA origami template for enhancing the stability of DNA materials. Reproduced with permission from Ref. [51]. Copyright 2018 Royal Society of Chemistry. c Shape-controlled conductive polyaniline on DNA templates. Reproduced with permission from Ref. [53]. Copyright 2014 American Chemical Society. d Shape-controlled nanofabrication of polydopamine on DNA templates Reproduced with permission from Ref. [54, 55]. Copyright 2018 Wiley-VCH

counterpart [51]. The rectangular DNA origami was folded into a tube structure, and a controlled ATRP reaction was realized on the outer surface of the tube to construct a polymer-protecting shell. Meanwhile, the inner cavity of the tube is still available for further modification to accommodate other reactions (Fig. 5b). Notably, the defined polymer modification significantly enhanced the stability of DNA nanotubes, similar to that observed with the polymer encapsulation methods discussed above in the section on Polymer modified DNA nanomaterials [51]. Moreover, the functional positions (such as the inner cavity) on DNA nanostructures could remain unaffected, which could be further modified with guest molecules. Therefore, this method holds great potential for drug delivery, with more opportunities to tune the in vivo behaviors and design complex functionalities.

In addition to controlled radical polymerization, DNA template technology can also be applied to the synthesis of other patterned polymers. Ding's group reported the catalytic polymerization of aniline on DNA nanostructures [52, 53]. In the presence of hydrogen peroxide, conductive polyaniline could be synthesized at the desired position on double-stranded DNA [52] and on triangular DNA origami nanostructures via a pre-immobilized horseradish peroxidase- or hemin-catalyzed polymerization reaction (Fig. 5c) [53]. This method of preparing conductive polymers in a controllable manner on DNA origami provides a new strategy for the design of nanocircuits. Based on this localized catalysis concept, Weil and 
co-workers reported shape-controllable in situ polydopamine synthesis on DNA nanostructures by positioning G-quadruplex groups as designed on a rectangular DNA tile and incorporating hemin as a cofactor [54, 55]. In the presence of hydrogen peroxide, the G-quadruplex/hemin DNAzymes mimic horseradish peroxidase activity and induce the oxidative polymerization of dopamine with predesigned patterns [54]. Alternatively, photoirradiation can also initiate the dopamine polymerization reaction in this system [55]. This methodology renders it possible to construct anisotropic polydopamine nanostructures such as nanorods and nano-crosses, which are difficult to achieve by conventional synthesis. These authors further demonstrated that the synthesized polydopamine nanostructure could be retained after removing the DNA template (Fig. 5d), therefore providing a new strategy for polydopamine nanofabrication.

In addition to DNA nanostructure-templated in situ polymer synthesis, Liu and colleagues have developed a series of methods to use DNA nanostructures as scaffolds to control the morphology of polymersomes and liposomes, which have been collectively named as the "frame guided assembly" technique. It is well known that spontaneously self-assembled vesicles of amphiphilic polymersomes and liposomes are usually spherical. However, Liu's methods allowed construction of cubic shaped polymersomes and nanometer liposome sheets depending on the DNA template used. Hereby, they could even overcome the surface tension force in nature (Fig. 6a) $[56,57]$.

Other than controlling the shape and morphology of polymers, DNA templates allow the installation of functional handles on defined positions of polymer nanoparticles. Toward this end, Sleiman and colleagues reported a method of synthesizing DNA-imprinted polymer nanoparticles with monodispersity and prescribed DNAstrand patterns inside a DNA cage (Fig. 6b) [58]. They first immobilized DNA-polymer conjugates on predefined positions of the DNA cage, and then crosslinked the polymers inside the cage. In this way, once the DNA cage is decomposed, DNA handles pre-conjugated with polymer precursors are left on the crosslinked polymer cores with predesigned geometries. This is the first method to achieve nanoparticles with exact number and orientation of asymmetric modifications, which could significantly advance the area of polymer assembly. The works described above strongly indicate the unique advantages of DNA nanotechnology for controlling polymer morphology and function. The features achieved by these methods are almost impossible to achieve with conventional polymer synthesis, and are therefore particularly attractive for preparation of exquisite polymer materials for advance applications, such as intelligent polymer nanorobots, elaborate biosensors and intricate soft electronic devices.

\subsection{Routing of Single Polymer Chain}

In addition to controlling the morphology of polymer nanomaterials, DNA nanostructures can even be used to manipulate the molecular conformation of an individual polymer chain. Gothelf and colleagues prepared synthetic polymer wires containing short oligonucleotides that extend from each repeat [named 

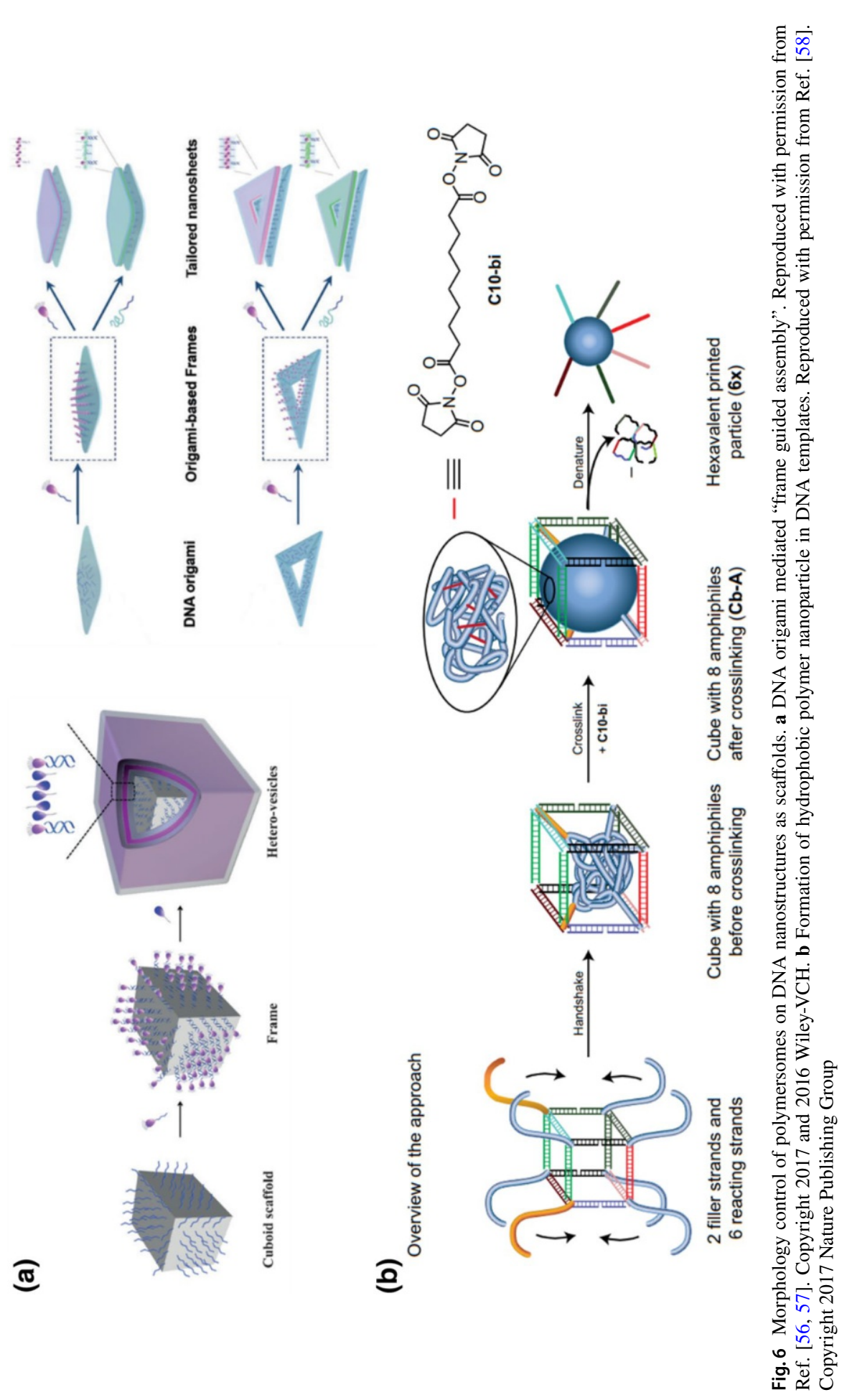

苞完

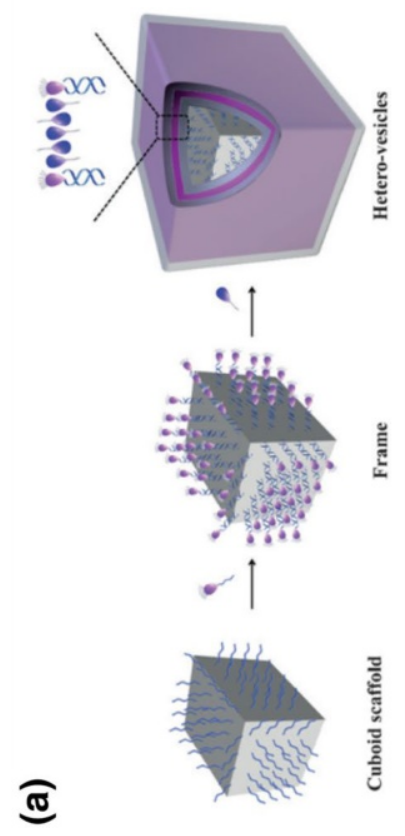


poly(APPV-DNA), see Fig. 7a]. The oligonucleotide side chains allow the polymer wire to assemble on the desired positions of DNA nanostructures where the complementary sticky sequences were pre-allocated. In this way, a single polymer chain could be picked up from the polymer solution and immobilized on a DNA template following a predesigned route (Fig. 7a) [59]. Moreover, they can even achieve controlled conformational switching of a single polymer chain on the DNA nanotile based on toehold-mediated strand displacement (Fig. 7b) [60]. The controlled aggregation of poly(APPV-DNA) polymers in solution through varying the ionic environment and sequence-specific DNA interactions was demonstrated in their recent work [61].

On the basis of these works, the team developed a novel hybrid DNA-polyfluorene material, poly(F-DNA), wherein the backbone of polyfluorene was a conjugated polymer with special optical and electronic properties. The fluorescence emission of poly(F-DNA) could be quenched efficiently upon binding to very small amounts of complementary DNA carrying a small molecule quencher. Furthermore, they showed controlled energy transfer between poly(F-DNA) and poly(APPV-DNA) mediated by Watson-Crick base pairing (Fig. 7c) [62]. This concept opens up possibilities for studying the molecular interactions between polymers with different structures via intramolecular energy transfer. These studies clearly demonstrate that DNA nanotechnology provides unprecedented opportunities for handling individual synthetic polymer chains, thus revealing immense prospects for studying and utilizing the single-molecule properties of polymers. These designer organic polymer-DNA complexes are expected to be used as single molecular wires to support the design of high-precision nanocircuits in the future.

(a)
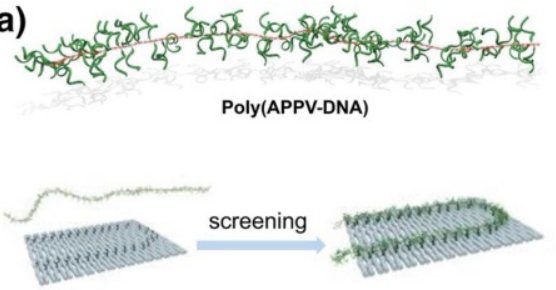

Single polymer screening process on DNA template

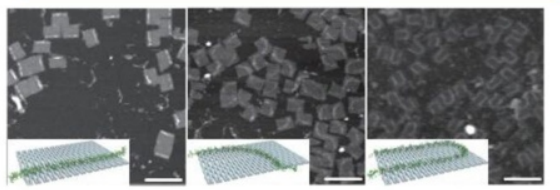

(b)

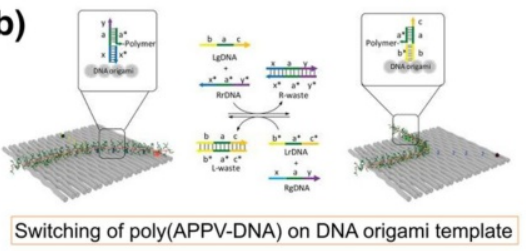

(c)

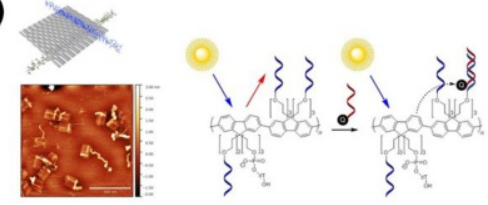

Immobilization of poly(F-DNA) and poly(APPV-DNA) in designed patterns on DNA origami template

Fig. 7a-c DNA-nanostructure-templated synthesis of single synthetic polymers. a Single polymer screening process based on DNA origami templates. Reproduced with permission from Ref. [59]. Copyright 2015 Nature Publishing Group. b Programmed switching of single polymer conformation on DNA origami template. Reproduced with permission from Ref. [60]. Copyright 2016 American Chemical Society. c Single polymer manipulation and energy transfer investigation of poly(F-DNA) conjugated polymer. Reproduced with permission from Ref. [62]. Copyright 2016 Wiley-VCH 


\section{Assembly of Inorganic Nanoparticles Based on DNA Nanostructures}

From the perspective of chemical structure, the DNA strand is an organic macromolecule composed of $\mathrm{C}, \mathrm{H}, \mathrm{O}, \mathrm{N}$, and P. Among the virtues of DNA molecules are their controllable structure, adjustable sequence and ease of modification. However, they lack the mechanical strength and quantum optical properties that are commonly available in inorganic nanomaterials. On the other hand, it remains challenging for conventional synthesis of inorganic nanoparticles to achieve arbitrary shapes and controllable assembly, which are highly important in achieving the desired optical and mechanical properties. Therefore, combining the benefits of both materials, DNA-assisted inorganic nanoparticle synthesis and assembly presents an attractive way to create rationally designed nanomaterials with unique features. In this context, modifying nanoparticles ( $\mathrm{Au}, \mathrm{Ag}$, etc.) with oligonucleotides was found valuable to create nanoparticle crystals with the desired lattice form. DNA nanostructures could even serve as molds to control the morphology of inorganic nanoparticles during synthesis. Moreover, using DNA nanostructures as templates could even fabricate chiral plasmonic metamolecules. This section will summarize recent developments in this area.

\subsection{DNA-Programmed Nanoparticle Super-Lattice Crystallization}

In 1996, the groups of Mirkin and Schultz published two articles in Nature at the same time that revealed the possibility of using oligonucleotide-conjugated gold nanoparticles to guide the formation of nanoparticle assembly [63, 64]. DNA oligonucleotide chains with end-caped sulfhydryl groups were modified on gold nanoparticles (AuNPs) by Au-S bonds, while the reversible assembly of gold nanoparticles was controlled by adding designed DNA linkers with complementary sequences. When DNA duplexes with complementary sequences on both sides were added, the AuNPs formed aggregations with regular interspaces [63]. When the complementary oligonucleotides were positioned at the desired distances along the DNA duplex, defined AuNP dimers and trimers with controllable spacing could be achieved [64]. Since then, the self-assembly of inorganic nanoparticles templated by DNA oligonucleotide chains has advanced rapidly, and has found broad application in the construction of diagnostic tools for nucleic acid, protein and bacteria [65-69], as intracellular probes [70-73], and as selective detection biosensors [74-76] and gene regulators, etc. [77].

Despite the attractive applications of these small nanoparticle aggregates, preparation of perfect macroscopic nanoparticle crystals with super lattices was a longstanding challenge until 2008 when the groups of Gang and Mirkin independently reported DNA-guided gold nanoparticle crystals (Fig. 8a, b) [78, 79]. They demonstrated that the growth and assembly of gold nanocrystal structures could be controlled by changing the length of DNA strands between gold nanoparticles. Lattice structures could be accomplished through precisely designing the base sequences 
(a)

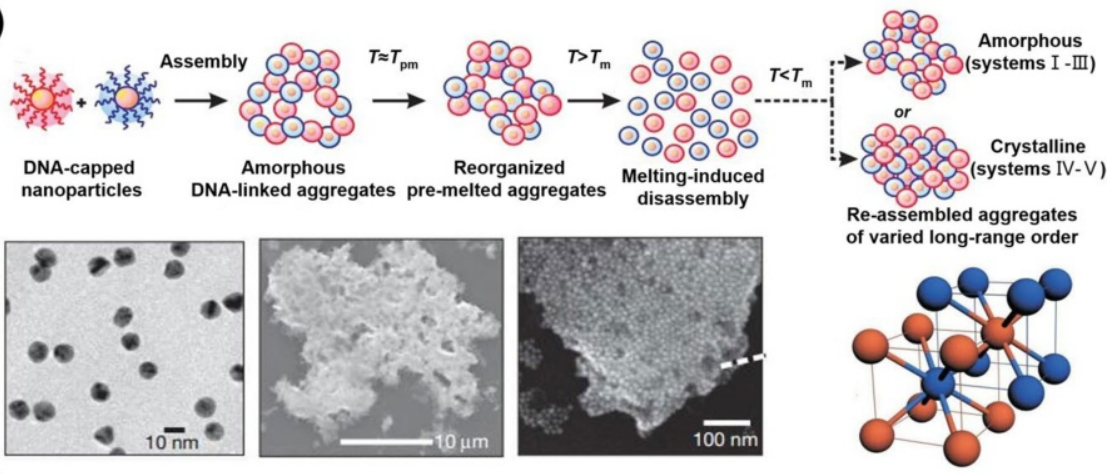

(b)

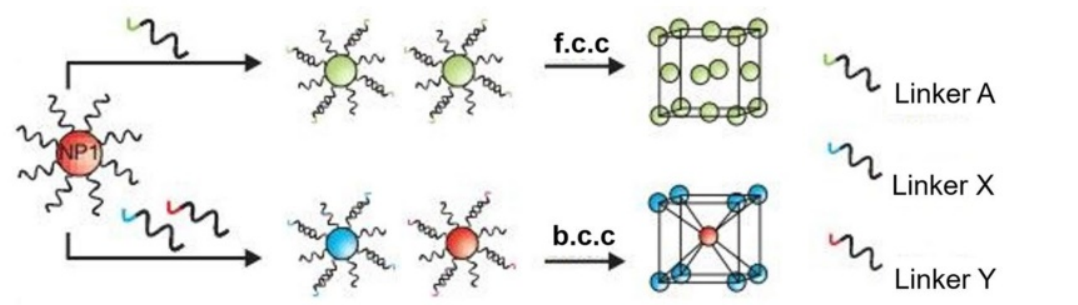

(c)

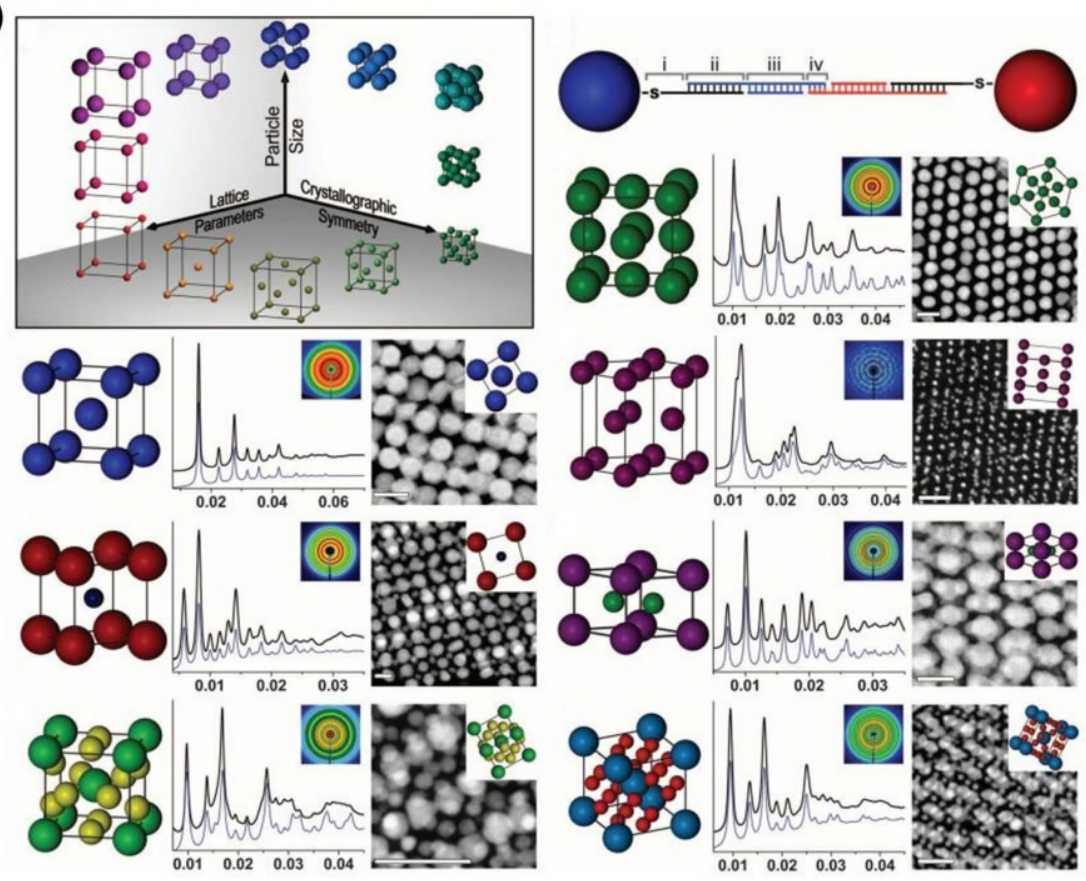

Fig. 8a-c DNA-strand-guided crystallization of inorganic nanoparticles. $\mathbf{a}, \mathbf{b}$ The length of the DNA strand and the size of gold nanoparticles influence the crystal pattern. Reproduced with permission from Refs. [78] and [79]. Copyright 2008 Nature Publishing Group. c Various crystal lattice structures and their characterization based on DNA-guided assembly of gold nanoparticles. Reproduced with permission from Ref. [80] Copyright 2011 American Association for the Advancement of Science 
and lengths of DNA strands. The Mirkin group subsequently engaged in the manipulation of gold nanoparticles using DNA chains to investigate more diverse crystal superlattices (Fig. 8c) [80]. Moreover, not only were various self-assembled structures from a single inorganic nanoparticle to a superlattice achieved [81-87], the properties of the assembled structures, such as temperature-dependent crystal topology [88], crystal surface energy [89], and dynamic DNA strand substitution [90], were also studied in detail. The mechanism of DNA-templated nanoparticle self-assembly was explained by the repulsive force between colloids [91] and the enthalpy change [92]. The dynamic properties of DNA-templated nanoparticle crystallization [93], in conjunction with previous works [94, 95], revealed that the number of DNA chains per nanoparticle and temperature were the main factors controlling the interaction strength between nanoparticle building blocks.

All the examples mentioned above require gold nanoparticles pre-modified with DNA linkers. Recently, Kostiainen and colleagues reported that ordered 3D gold nanoparticle superlattices could be accessed through sole electrostatic interactions between positively charged gold nanoparticles and negatively charged DNA nanostructures [96]. This approach provided an easier alternative to create a nanoparticle crystal lattice when the accurate design of different types of lattice structure is not required.

These studies realized programmable synthesis of macroscopic materials from rationally designed microscopic nanoparticles, thus providing unprecedented control over the microstructures of bulk materials. Conventional material synthesis generally results in modest control over the placement of, the periodicity in, and the distance between, particles within the assembled material. DNA-assisted strategies allow nanoparticles to be assembled in a designed manner with high precision, which is essential for the design of metamaterials with superior properties in the future.

\subsection{Inorganic Nanoparticle Growth with Controllable Dimensionality}

In addition to guiding the assembly of pre-synthesized nanoparticles, DNA nanostructures could also serve as a mold to confine crystal growth during nanoparticle synthesis. In 2014, Yin and co-workers proposed the strategy of casting the growth of inorganic nanoparticles with controllable shapes inside DNA nanostructures cavities. Small gold nanoparticle seeds modified with DNA strands were hybridized onto sticky ends inside the origami cavity. Thereafter, gold nanoparticles were grown in the DNA cavities to completely fill the space. Various shapes of silver or gold nanoparticles can be obtained by designing DNA origami with the apppropriate cavity structures. Moreover, composite inorganic nanoparticles were also accessible by introducing two quantum dots at both ends of the cavity (Fig. 9a) [97]. Analogously, Seidel and colleagues used the DNA origami cavity as a mold to control the growth of gold nanoparticles, and this process was successfully observed by TEM spectroscopy with stepwise addition of chloroauric acid [98, 99]. Inspired by these studies, Fan and Yan and their coworkers recently also presented a general method for creating biomimetic complex silica composite nanomaterials based on 


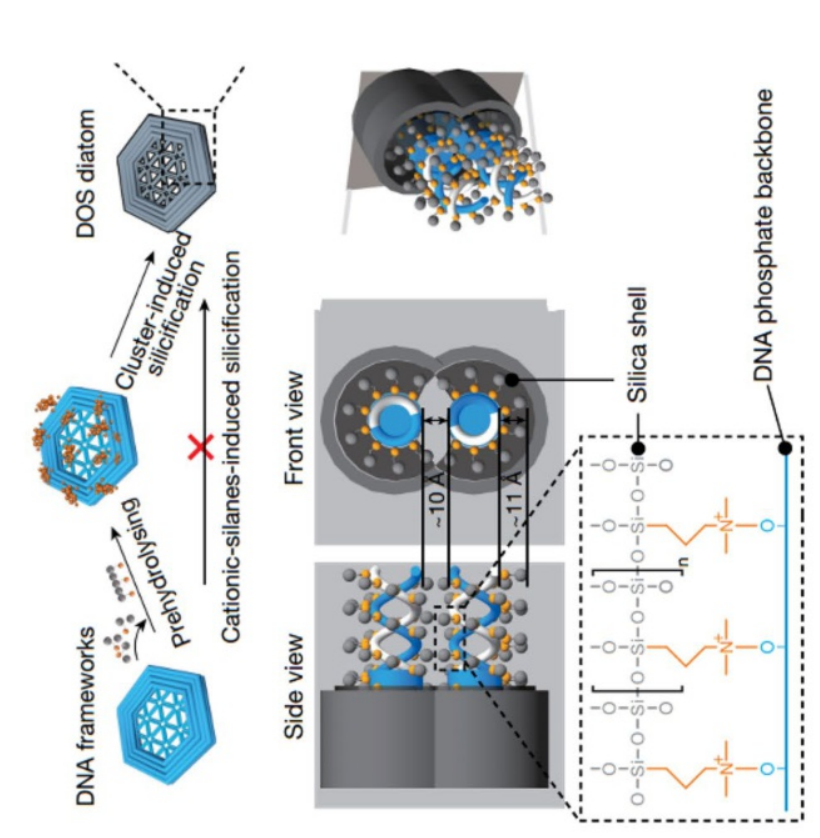

으

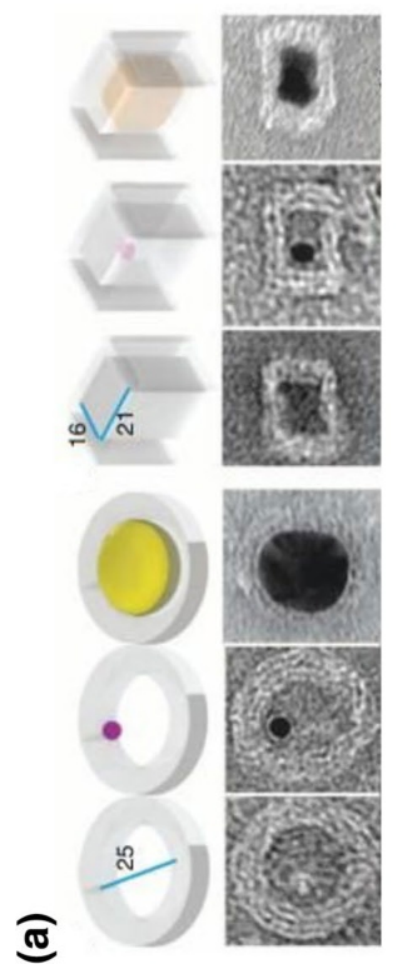

कิ

总

苨

施 青

进券

응 잉

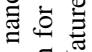

증

荧 $\stackrel{\infty}{\stackrel{1}{*}}$

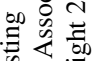

跣

.

㐫完官

유을

जิ

哥 䂞

ㄴ.

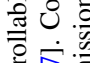

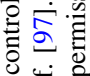

幽吾

青

㺃

을

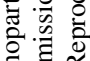

들

픙 局

䓅

记

ક

응 응

का

盶

羟

월

政

究㤩

ए

包 政

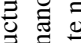

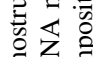

음

ㅎํㅇ

艺它导

을

ลิ \&

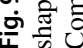


1D, 2D, and 3D DNA nanostructures ranging in size from 10 to $1000 \mathrm{~nm}$ (Fig. 9b) [100]. Silicification was achieved through mixing DNA origami templates with prehydrolyzed TMAPS [ $N$-trimethoxysilylpropyl- $N, N, N$-trimethylammonium chloride and TEOS (tetraethyl orthosilicate)], thus a silica shell was formed on DNA origami templates. This represents the first protocol to access highly sophisticated but flexibly designed silica oxide nanostructures that could not be realized by conventional silica nanofabrication techniques. The feasibility of this method was also demonstrated in a parallel study by Heuer-Jungemann [101], which collectively revealed the charm of DNA-templated synthesis to achieve various materials with ingenious nanostructures.

\subsection{Chiral and Plasmonic Arrangement of Inorganic Nanoparticles}

On the basis of controlling the crystallization and in situ growth of gold nanoparticles, DNA-templated synthesis and assembly techniques can also manipulate the assembly behavior of other diverse inorganic nanoparticles, and even change their inherent physical and chemical properties. It is known that when metal particles are placed in close proximity, their particle plasmons (collective oscillations of conduction electrons) become coupled and induce numerous interesting optical phenomena [102-104]. However, in practice, it is a challenge to ensure that the spacing between two nanoparticles can be arranged as closely as predesigned. As a fully addressable, easily functionalized platform, DNA nanostructures have been used recently to control the spatial organization of discrete nanoparticles with nanometer accuracy [105]. Nanoparticles can be arrayed in any nanometer distance and space on DNA nanostructures with defined patterns. For example, left-handed and right-handed arrangements of gold nanoparticles and nanorods on DNA nanostructures have been prepared to study chiral plasmonic properties at the nanoscale. Furthermore, a variety of chiral plasmonic metal-organic nanostructures [106-108] and chiral colloidal liquid crystals [109] are accessible via DNA- templated nanotechnology.

In this context, some pioneering work was carried out by Ding and co-workers, who prepared AuNPs arranged linearly on a rectangular DNA origami sheet with precisely controlled positions and particle spacing, and then assembled them into a 3D helical geometry with chiral plasmonic phenomenon by rational rolling of the DNA origami sheet. This study opened up the possibility of realizing programmable 3D plasmonic structures with desired optical properties [110]. Thereafter, Liedl and colleagues designed a 3D DNA origami nanostructure (a nanorod with around $100 \mathrm{~nm}$ in length) as nanotemplate to directly organize the helical arrangement of gold nanoparticles for the generation of chiral plasmonic nanostructures. The gold-DNA nanostructure exhibited defined circular dichroism and optical rotatory dispersion effects at visible wavelengths that originated from the collective plasmon-plasmon interactions of the nanoparticles positioned with an accuracy better than $2 \mathrm{~nm}$ (Fig. 10a) [111]. Moreover, Wang and co-workers constructed anisotropic gold nanorod (AuNR) helical superstructures with tailored chirality based on DNA origami nanostructure templates. The ' $\mathrm{X}$ ' pattern of the DNA capturing strands was predesigned on both sides of a 2D DNA origami template, and several AuNRs 


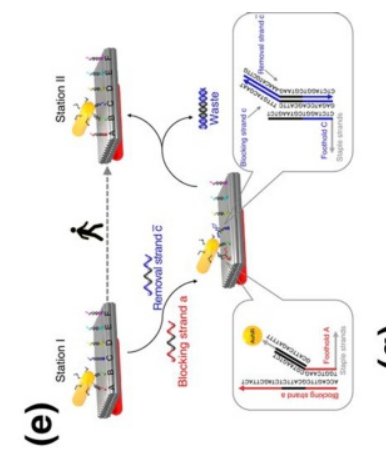

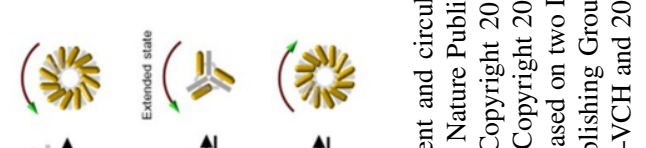

हี

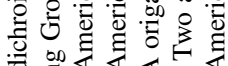

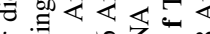

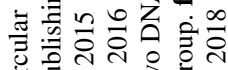

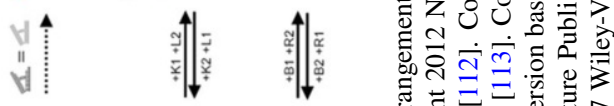

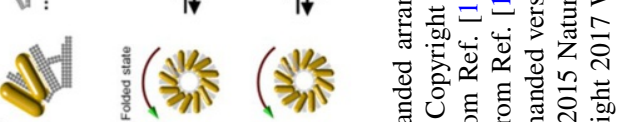

ชิ

-

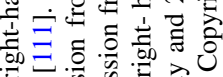

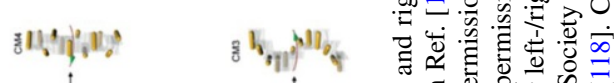

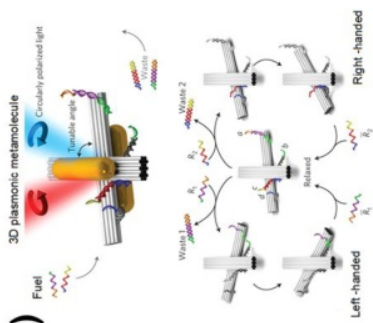

ซ

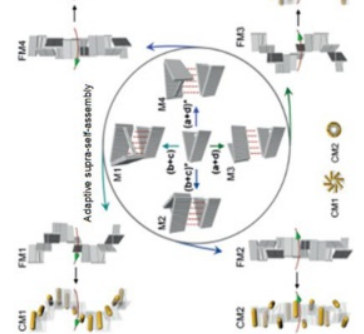

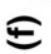

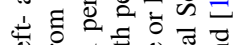

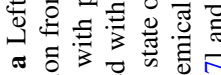

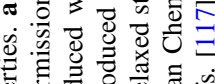

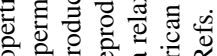

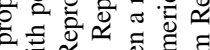

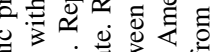

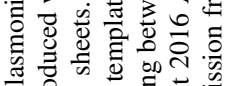

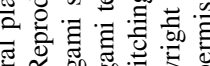

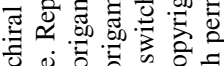
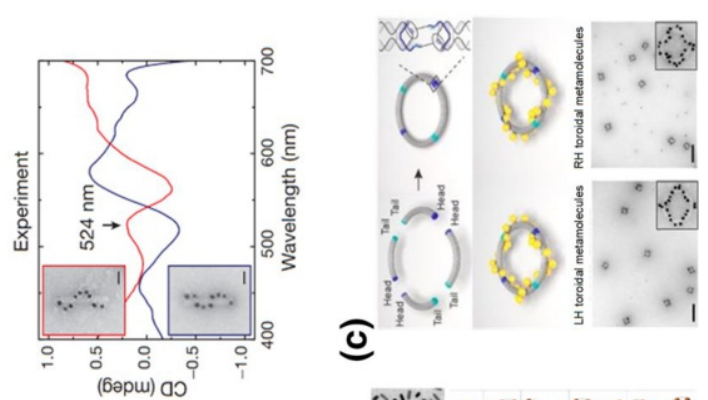

西过记

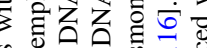

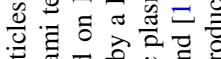

큼을

䒘:

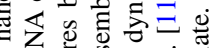

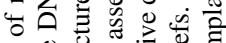

$\exists$ 过

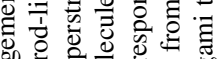

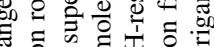

है का है:

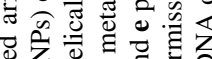

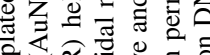

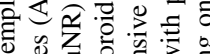

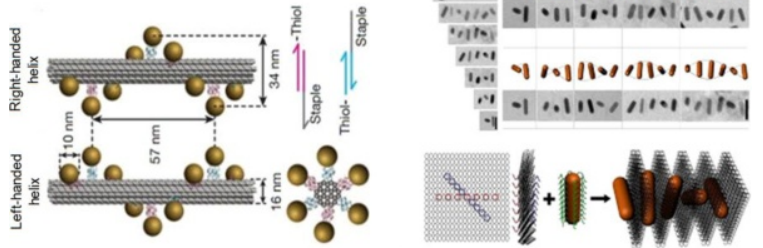

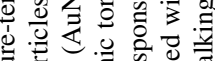

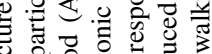

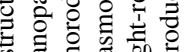

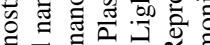

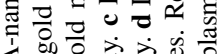

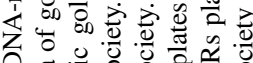

Z

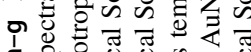

\% के

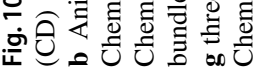


were modified on the origami template by base pairing, and assembled into AuNRs helices with the origami intercalated between neighboring AuNRs (Fig. 10b) [112]. Similarly, Liu's group presented chiral plasmonic Au NPs based on a 3D DNA origami ring template (Fig. 10c) [113]. These left-handed and right-handed helical metal-DNA nanostructures all show characteristic circular dichroism effects.

In addition to the above-mentioned static chiral plasmonic nanostructures, Liu et al. also developed dynamic chiral plasmonic nanostructures based on DNA origami templates. For example, light-responsive azobenzene-modified DNA strands (Fig. 10d) [114] and pH-responsive DNA triplexes [115] serve as construction materials to organize plasmonic nanoparticles in three dimensions while concurrently driving the metal-DNA molecules to distinct conformational states. The dynamic behavior of AuNRs towards light and $\mathrm{H}^{+}$stimuli was observed by $\mathrm{CD}$ signal changes. Similarly, strand displacement reactions were also applied to drive the plasmonic walking of AuNRs, which were recorded as dynamic CD signal changes (Fig. 10e) [116]. Recently, Lan et al. presented a new method for the tunable selfassembly of DNA chiral supramolecular architectures by creating a versatile DNA origami adapter (Fig. 10f) [117] and a reconfigurable chiral nanoparticle helix superstructure with fully switchable chirality (Fig. 10g) [118].

\section{Summary and Perspectives}

This review summarizes recent progress in nanomaterials synthesis based on DNA nanostructure templates. With computer-aided design, the use of DNA synthesizers, and the rapid development of DNA nanotechnology, we can construct a large variety of DNA nanomaterials. This technique provides valuable opportunities for more controllable preparation of organic and inorganic materials, polymer materials and other synthetic materials, indicating that its influence has distinctly penetrated all aspects of material science. Mimicking the central dogma, translating DNA sequence to other synthetic polymeric materials provides a valuable method of achieving sequence-controlled polymers. Based on larger DNA nanostructures, one can confine polymer synthesis to obtain more sophisticated polymer nanostructures or anisotropic polymer films, or even control the alignment of a single polymer chain to fabricate single molecular level electronic circuits. The self-assembly of inorganic nanoparticles based on DNA nanostructure templates can also be manipulated by DNA nanotechnology to achieve precise regulation at the nanoscale, including lattice regulation, chiral regulation and dynamic growth regulation. Moreover, in situ synthesis of inorganic nanomaterials inside a DNA model or outside a DNA template has also emerged as a powerful method to achieve inorganic nanostructures with intricate details.

The structural variability and the capability of precise customization make DNA nanostructures an extremely powerful tool for improving high precision and controllable preparation techniques for nanomaterials. Undoubtedly, DNA-encoded synthesis technology will also bring more innovations in the field of chemical materials preparation, especially given the advantages in high-precision control of nanomaterial assembly and highly complex nanomaterial processing. This has broad 
application prospects in biomedicine, fine electronics, flexible materials and other fields. Despite their extraordinary prospects, several limitations have to be overcome before the widespread use of DNA nanostructures. Firstly, the cost of DNA materials has to be further reduced, which might be possible with advances in DNA synthesis techniques or the development of synthetic biology to allow direct production of DNA nanostructures in microorganisms; secondly, the yield and robustness of these methods have to be further proved. Since most of these methods require several steps of self-assembly and reactions, reliable scale up has been shown only rarely and further optimization is required. Thirdly, DNA nanotechnology has irreplaceable advantages in achieving elaborate nanostructures from several to hundreds of nanometers, but assembly of even larger structures is relatively inefficient. Therefore, the combination of DNA-based materials synthesis together with other nanofabrication techniques, such as lithography or 3D printing, would be essential to achieve desired materials with rational designed structure from micro- to macro-level.

Overall, the development of DNA-programmed material synthesis is just beginning, and extensive efforts are still required. However, along with increasing knowledge about structure-function relationships in materials, improving the precision of nanofabrication techniques for advanced material synthesis is apparently in highly demand. Therefore, one can envision that this field will develop rapidly in the next few years. The first application breakthroughs might be in medicinal and healthcare materials, considering their favorable biocompatibility and relatively high cost.

Acknowledgements Open access funding provided by Projekt DEAL. This work was funded by the National Natural Science Foundation of China, grant number 51703073 and the Fundamental Research Funds for the Central Universities of China (2017KFYXJJ167), the 1000 Young Talent Program of China.

\section{Compliance with ethical standards}

Conflict of interest On behalf of all authors, the corresponding author states that there is no conflict of interest.

Open Access This article is licensed under a Creative Commons Attribution 4.0 International License, which permits use, sharing, adaptation, distribution and reproduction in any medium or format, as long as you give appropriate credit to the original author(s) and the source, provide a link to the Creative Commons licence, and indicate if changes were made. The images or other third party material in this article are included in the article's Creative Commons licence, unless indicated otherwise in a credit line to the material. If material is not included in the article's Creative Commons licence and your intended use is not permitted by statutory regulation or exceeds the permitted use, you will need to obtain permission directly from the copyright holder. To view a copy of this licence, visit http://creativecommons.org/licen ses/by/4.0/.

\section{References}

1. Watson JD, Crick FHC (1953) Molecular structure of nucleic acids: a structure for deoxyribose nucleic acid. Nature 171(4356):737-738 
2. Watson JD, Crick FHC (1953) Genetical implications of the structure of deoxyribonucleic acid. Nature 171(4361):964-967

3. Crick FHC (1954) The complementary structure of DNA. Proc Natl Acad Sci USA 40(8):756-758

4. Shao Y, Jia H, Cao T, Lu D (2017) Supramolecular hydrogels based on DNA self-assembly. Acc Chem Res 50(4):659-668

5. Seeman NC (1982) Nucleic acid junctions and lattices. J Theor Biol 99(2):237-247

6. Seeman NC, Kallenbach NR (1983) Design of immobile nucleic acid junctions. Biophys J 44(2):201-209

7. Chen JH, Seeman NC (1991) Synthesis from DNA of a molecule with the connectivity of a cube. Nature 350(6319):631-633

8. Seeman NC (2003) DNA in a material world. Nature 421(6921):427-431

9. Rothemund PWK (2006) Folding DNA to create nanoscale shapes and patterns. Nature 440(7082):297-302

10. Douglas SM, Marblestone AH, Teerapittayanon S, Vazquez A, Church GM, Shih WM (2009) Rapid prototyping of 3D DNA-origami shapes with caDNAno. Nucleic Acids Res 37(15):5001-5006

11. Douglas SM, Dietz H, Liedl T, Högberg BH, Graf F, Shih WM (2009) Self-assembly of DNA into nanoscale three-dimensional shapes. Nature 459(7245):414-418

12. Wei B, Dai M, Yin P (2012) Complex shapes self-assembled from single-stranded DNA tiles. Nature 485(7400):623-626

13. Benson E, Mohammed A, Gardell J, Masich S, Czeizler E, Orponen P, Högberg B (2015) DNA rendering of polyhedral meshes at the nanoscale. Nature 523(7561):441-444

14. Han D, Qi X, Myhrvold C, Wang B, Dai M, Jiang S, Bates M, Liu Y, An B, Zhang F, Yan H, Yin P (2017) Single-stranded DNA and RNA origami. Science 358(6369):eaao2648

15. Wagenbauer KF, Sig C, Dietz H (2017) Gigadalton-scale shape-programmable DNA assemblies. Nature 552(7683):78-83

16. Praetorius F, Kick B, Behler KL, Honemann MN, Weuster-Botz D, Dietz H (2017) Biotechnological mass production of DNA origami. Nature 552(7683):84-87

17. Badi N, Lutz J-F (2009) Sequence control in polymer synthesis. Chem Soc Rev 38(12):3383-3390

18. Schmidt BVKJ, Fechler N, Falkenhagen J, Lutz J-F (2011) Controlled folding of synthetic polymer chains through the formation of positionable covalent bridges. Nat Chem 3(3):234-238

19. Lutz J-F, Ouchi M, Liu DR, Sawamoto M (2013) Sequence-controlled polymers. Science 341(6146):1238149

20. Pfeifer S, Lutz J-F (2007) A facile procedure for controlling monomer sequence distribution in radical chain polymerizations. J Am Chem Soc 129(31):9542-9543

21. Nakatani K, Ogura Y, Koda Y, Terashima T, Sawamoto M (2012) Sequence-regulated copolymers via tandem catalysis of living radical polymerization and in situ transesterification. J Am Chem Soc 134(9):4373-4383

22. McHale R, Patterson JP, Zetterlund PB, O'Reilly RK (2012) Biomimetic radical polymerization via cooperative assembly of segregating templates. Nat Chem 4(6):491-497

23. Belowich ME, Valente C, Smaldone RA, Friedman DC, Thiel J, Cronin L, Stoddart JF (2012) Positive cooperativity in the template-directed synthesis of monodisperse macromolecules. J Am Chem Soc 134(11):5243-5261

24. Edwardson TGW, Carneiro KMM, Serpell CJ, Sleiman HF (2014) An efficient and modular route to sequence-defined polymers appended to DNA. Angew Chem Int Ed 53(18):4567-4571

25. de Rochambeau D, Sun Y, Barlog M, Bazzi HS, Sleiman HF (2018) Modular strategy to expand the chemical diversity of DNA and sequence-controlled polymers. J Org Chem 83(17):9774-9786

26. Pinheiro VB, Taylor AI, Cozens C, Abramov M, Renders M, Zhang S, Chaput JC, Wengel J, PeakChew S-Y, McLaughlin SH, Herdewijn P, Holliger P (2012) Synthetic genetic polymers capable of heredity and evolution. Science 336(6079):341-344

27. Pinheiro VB, Holliger P (2014) Toward XNA nanotechnology: new materials from synthetic genetic polymers. Trends Biotechnol 32(6):321-328

28. Yu H, Zhang S, Chaput JC (2012) Darwinian evolution of an alternative genetic system provides support for TNA as an RNA progenitor. Nat Chem 4(3):183-187

29. Usanov DL, Chan AI, Maianti JP, Liu DR (2018) Second-generation DNA-templated macrocycle libraries for the discovery of bioactive small molecules. Nat Chem 10(7):704-714

30. Chen Z, Lichtor PA, Berliner AP, Chen JC, Liu DR (2018) Evolution of sequence-defined highly functionalized nucleic acid polymers. Nat Chem 10(4):420-427 
31. Chan AI, McGregor LM, Liu DR (2015) Novel selection methods for DNA-encoded chemical libraries. Curr Opin Chem Biol 26:55-61

32. Rosenbaum DM, Liu DR (2003) Efficient and sequence-specific DNA-templated polymerization of peptide nucleic acid aldehydes. J Am Chem Soc 125(46):13924-13925

33. Kleiner RE, Brudno Y, Birnbaum ME, Liu DR (2008) DNA-templated polymerization of sidechain-functionalized peptide nucleic acid aldehydes. J Am Chem Soc 130(14):4646-4659

34. Brudno Y, Birnbaum ME, Kleiner RE, Liu DR (2010) An in vitro translation, selection and amplification system for peptide nucleic acids. Nat Chem Biol 6(2):148-155

35. Chen W, Schuster GB (2012) DNA-programmed modular assembly of cyclic and linear nanoarrays for the synthesis of two-dimensional conducting polymers. J Am Chem Soc 134(2):840-843

36. Snyder TM, Liu DR (2005) Ordered multistep synthesis in a single solution directed by DNA templates. Angew Chem Int Ed 44(45):7379-7382

37. Mckee ML, Milnes PJ, Bath J, Stulz E, O’Reilly RK, Turberfield AJ (2012) Programmable one-pot multistep organic synthesis using DNA junctions. J Am Chem Soc 134(3):1446-1449

38. He Y, Liu DR (2010) Autonomous multistep organic synthesis in a single isothermal solution mediated by a DNA walker. Nat Nanotechnol 5(11):778-782

39. Niu J, Hili R, Liu DR (2013) Enzyme-Free translation of DNA into sequence-defined synthetic polymers structurally unrelated to nucleic acids. Nat Chem 5(4):282-292

40. Jiang Q, Liu S, Liu J, Wang Z-G, Ding B (2018) Rationally designed DNA-origami nanomaterials for drug delivery in vivo. Adv Mater 4:e1804785

41. Perrault SD, Shih WM (2014) Virus-inspired membrane encapsulation of DNA nanostructures to achieve in vivo stability. ACS Nano 8(5):5132-5140

42. Mikkilä J, Eskelinen A-P, Niemelä EH, Linko V, Frilander MJ, Törmä P, Kostiainen MA (2014) Virus-encapsulated DNA origami nanostructures for cellular delivery. Nano Lett 14(4):2196-2200

43. Kiviaho JK, Linko V, Ora A, Tiainen T, Järvihaavisto E, Mikkilä J, Tenhu H, Nonappa, Kostiainen MA (2016) Cationic polymers for DNA origami coating-examining their binding efficiency and tuning the enzymatic reaction rates. Nanoscale 8(22):11674-11680

44. Auvinen H, Zhang H, Nonappa, Kopilow A, Niemelä EH, Nummelin S, Correia A, Santos HA, Linko V, Kostiainen MA (2017) Protein coating of DNA nanostructures for enhanced stability and immunocompatibility. Adv. Healthcare Mater. 6(18):201700692

45. Agarwal NP, Matthies M, Gür FN, Osada K, Schmidt TL (2017) Block copolymer micellization as a protein strategy for DNA origami. Angew Chem Int Ed 56(20):5460-5464

46. Ponnuswamy N, Bastings MMC, Nathwani B, Ryu JH, Chou LYT, Vinther M, Li WA, Anastassacos FM, Mooney DJ, Shih WM (2017) Oligolysine-based coating protects DNA nanostructures from Low-salt denaturation and nuclease degradation. Nat Commun 8:15654

47. Ahmadi Y, Llano ED, Barišić I (2018) (poly)cation-induced protection of conventional and wireframe DNA origami nanostructures. Nanoscale 10(16):7494-7504

48. Xu X, Fang S, Zhuang Y, Wu S, Pan Q, Li L, Wang X, Sun X, Liu B, Wu Y (2019) Cationic albumin encapsulated DNA origami for enhanced cellular transfection and stability. Materials 12(6):949

49. Averick SE, Dey SK, Grahacharya D, Matyjaszewski K, Das SR (2014) Solid-Phase incorporation of an ATRP initiator for polymer-DNA biohybrids. Angew Chem Int Ed 53(10):2739-2744

50. Tokura Y, Jiang Y, Welle A, Stenzel MH, Krzemien KM, Michaelis J, Berger R, Barner-Kowollik C, Wu Y, Weil T (2016) Bottom-up fabrication of nanopatterned polymers on DNA origami by in situ atom-transfer radical polymerization. Angew Chem Int Ed 55(19):5692-5697

51. Tokura Y, Harvey S, Xu X, Chen C, Morsbach S, Wunderlich K, Fytas G, Wu Y, Ng DYW, Weil $\mathrm{T}$ (2018) Polymer tube nanoreactors via DNA-origami templated synthesis. Chem Commun 54(22):2808-2811

52. Wang Z-G, Zhan P, Ding B (2013) Self-assembly catalytic DNA nanostructures for synthesis of para-directed polyaniline. ACS Nano 7(2):1591-1598

53. Wang Z-G, Liu Q, Ding B (2014) Shape-controlled nanofabrication of conducting polymer on planar DNA templates. Chem Mater 26(11):3364-3367

54. Tokura Y, Harvey S, Chen C, Wu Y, Ng DYW, Weil T (2018) Fabrication of defined polydopamine nanostructure by DNA origami-templated polymerization. Angew Chem Int Ed 57(6):1587-1591

55. Winterwerber P, Harvey S, Ng DYW, Weil T (2019) Photocontrolled dopamine polymerization on DNA origami with nanometer resolution. Angew Chem Int Ed. https://doi.org/10.1002/anie.20191 1249 
56. Dong Y, Yang Y, Zhang Y, Wang D, Wei X, Banerjee S, Liu Y, Yang Z, Yan H, Liu D (2017) Cuboid vesicles formed by frame-guided assembly on DNA origami scaffolds. Angew Chem Int Ed 56(6):1586-1589

57. Zhou C, Zhang Y, Dong Y, Wu F, Wang D, Xin L, Liu D (2016) Precisely controlled 2D freefloating nanosheets of amphiphilic molecules through frame-guided assembly. Adv Mater 28(44):9819-9823

58. Trinh T, Liao C, Toader V, Barłóg M, Bazzi HS, Li J, Sleiman HF (2018) DNA-imprinted polymer nanoparticles with monodispersity and prescribed DNA-strand patterns. Nat Chem 10(2):184-192

59. Knudsen JB, Liu L, Kodal ALB, Madsen M, Li Q, Song J, Woehrstein JB, Wickham SFJ, Strauss MT, Schueder F, Vinther J, Krissanaprasit A, Gudnason D, Smith AAA, Ogaki R, Zelikin AN, Besenbacher F, Birkedal V, Yin P, Shih WM, Jungmann R, Dong M, Gothelf KV (2015) Routing of individual polymers in designed patterns. Nat Nanotechnol 10(10):892-898

60. Krissanaprasit A, Madsen M, Knudsen JB, Gudnason D, Surareungchai W, Birkedal V, Gothelf KV (2016) Programmed switching of single polymer conformation on DNA origami. ACS Nano 10(2):2243-2250

61. Gudnason D, Madsen M, Krissanaprasit A, Gothelf KV, Birkedal V (2018) Controlled aggregation of DNA functionalized poly(phenylene-vinylene). Chem Commun 54(44):5534-5537

62. Madsen M, Christensen RS, Krissanaprasit A, Bakke MR, Riber CF, Nielsen KS, Zelikin AN, Gothelf KV (2017) Preparation, single-molecule manipulation, and energy transfer investigation of a polyfluorene-graft-DNA polymer. Chem Eur J 23(44):10511-10515

63. Mirkin CA, Letsinger RL, Mucic RC, Storhoff JJ (1996) A DNA-based method for rationally assembling nanoparticles into macroscopic materials. Nature 382(6592):607-609

64. Alivisatos AP, Johnsson KP, Peng X, Wison TE, Loweth CJ, Bruchez MP Jr, Schultz PG (1996) Organization of 'nanocrystal molecules' using DNA. Nature 382(6592):609-611

65. Rosi NL, Mirkin CA (2005) Nanostructures in biodiagnostics. Chem Rev 105(4):1547-1562

66. Seferos DS, Giljohann DA, Hill HD, Prigodich AE, Mirkin CA (2007) Nano-flares: probes for transfection and mRNA detection in living cells. J Am Chem Soc 129(50):15477-15479

67. Tram DTN, Wang H, Sugiarto S, Li T, Ang WH, Lee C, Pastorin G (2016) Advances in nanomaterials and their applications in point of care (POC) devices for the diagnosis of infectious diseases. Biotechnol Adv 34(8):1275-1288

68. Amini B, Kamali M, Salouti M, Yaghmaei P (2017) Fluorescence bio-barcode DNA assay based on gold and magnetic nanoparticles for detection of Exotoxin A gene sequence. Biosens Bioelectron 92:679-686

69. He F, Xiong Y, Liu J, Tong F, Yan D (2016) Construction of Au-IDE/CFP10-ESAT6 aptamer/ DNA-AuNPs MSPQC for rapid detection of mycobacterium tuberculosis. Biosens Bioelectron 77:799-804

70. Wang G, Li Z, Luo X, Yue R, Shen Y, Ma N (2018) DNA-templated nanoparticle complexes for photothermal imaging and labeling of cancer cells. Nanoscale 10(35):16508-16520

71. Yang Y, Zhong S, Wang K, Huang J (2019) Gold nanoparticle based fluorescent oligonucleotide probes for imaging and therapy in living systems. Analyst 144(4):1052-1072

72. Dong B, Du S, Wang C, Fu H, Li Q, Xiao N, Yang J, Xue X, Cai W, Liu D (2019) Reversible self-assembly of nanoprobes in live cells for dynamic intracellular $\mathrm{pH}$ imaging. ACS Nano 13(2):1421-1432

73. Sun J, Pi F, Ji J, Lei H, Gao Z, Zhang Y, de Dieu Habimana J, Li Z, Sun X (2018) Ultrasensitive, "FRET-SEF" probe for sensing and imaging microRNAs in living cells based on gold nanoconjugates. Anal Chem 90(5):3099-3108

74. Nie W, Wang Q, Zou L, Zheng Y, Liu X, Yang X, Wang K (2018) Low-fouling surface plasmon resonance sensor for highly sensitive detection of microRNA in a complex matrix based on the DNA tetrahedron. Anal Chem 90(21):12584-12591

75. Li N, Xiang M, Liu J, Tang H, Jiang J (2018) DNA Polymer Nanoparticles programmed via supersandwich hybridization for imaging and therapy of cancer cells. Anal Chem 90(21):12951-12958

76. Tavallaie R, McCarroll J, Le Grand M, Ariotti N, Schuhmann W, Bakker E, Tilley RD, Hibbert DB, Kavallaris M, Gooding JJ (2018) Nucleic acid hybridization on an electrically reconfigurable network of gold-coated magnetic nanoparticles enables microRNA detection in blood. Nat Nanotechnol 13(11):1066-1071

77. Rosi NL, Giljohann DA, Thaxton CS, Lytton-Jean AKR, Han MS, Mirkin CA (2006) Oligonucleotide-modified gold nanoparticles for intracellular gene regulation. Science 312(5776):1027-1030 
78. Nykypanchuk D, Maye MM, van der Lelie D, Gang O (2008) DNA-guided crystallization of colloidal nanoparticles. Nature 451(7178):549-552

79. Park SY, Lytton-Jean AKR, Lee B, Weigand S, Schatz GC, Mirkin CA (2008) DNA-programmable nanoparticle crystallization. Nature 451(7178):553-556

80. Macfarlane RJ, Lee B, Jones MR, Harris N, Schatz GC, Mirkin CA (2011) Nanoparticle superlattice engineering with DNA. Science 334(6053):204-208

81. Laramy CR, O'Brien MN, Mirkin CA (2019) Crystal engineering with DNA. Nat Rev Mater 49(3):201-224

82. Auyeung E, Cutler JI, Macfarlane RJ, Jones MR, Wu J, Liu G, Zhang K, Osberg KD, Mirkin CA (2012) Synthetically programmable nanoparticle superlattices using a hollow three-dimensional spacer approach. Nat Nanotechnol 7(1):24-28

83. Senesi AJ, Eichelsdoerfer DJ, Macfarlane RJ, Jones MR, Auyeung E, Lee B, Mirkin CA (2013) Stepwise evolution of DNA-programmable nanoparticle superlattices. Angew Chem Int Ed 52(26):6624-6628

84. Auyeung E, Li TI, Senesi AJ, Schmucker AL, Pals BC, de la Cruz MO, Mirkin CA (2014) DNAmediated nanoparticle crystallization into Wulff polyhedra. Nature 505(7481):73-77

85. Sensi AJ, Eichelsdoerfer DJ, Brown KA, Lee B, Auyeung E, Choi CH, Macfarlane RJ, Young KL, Mirkin CA (2014) Oligonucleotide flexibility dictates crystal quality in DNA-programmable nanoparticle superlattices. Adv Mater 26(42):7235-7240

86. Zhang Y, Pal S, Srinivasan B, Vo T, Kumar S, Gang O (2015) Selective transformations between nanoparticle superlattices via the reprogramming of DNA-mediated interactions. Nat Mater 14(8):840-847

87. Lin Q, Mason JA, Li Z, Zhou W, O’Brien MN, Brown KA, Jones MR, Butun S, Lee B, Dravid VP, Aydin K, Mirkin CA (2018) Building superlattices from individual nanoparticles via templateconfined DNA-mediated assembly. Science 359(6376):669-672

88. Macfarlane RJ, Jones MR, Lee B, Auyeung E, Mirkin CA (2013) Topotactic interconversion of nanoparticle superlattices. Science 341(615):1222-1225

89. Jones MR, Kohlstedt KL, O’Brien MN, Wu J, Schatz GC, Mirkin CA (2017) Deterministic symmetry breaking of plasmonic nanostructures enabled by DNA-programmable assembly. Nano Lett 17(9):5830-5835

90. Kim Y, Macfarlane RJ, Mirkin CA (2013) Dynamic interchangeable nanoparticle superlattices through the use of nucleic acid-based allosteric effectors. J Am Chem Soc 135(28):10342-10345

91. Seo SE, Li T, Sensi AJ, Mirkin CA, Lee B (2017) The role of repulsion in colloidal crystal engineering with DNA. J Am Chem Soc 139(46):16528-16535

92. Thaner RV, Kim Y, Li TI, Macfarlane RJ, Nguyen ST, de la Cruz MO, Mirkin CA (2015) Entropy-driven crystallization behavior in DNA-mediated nanoparticle assembly. Nano Lett 15(8):5545-5551

93. Yu Q, Zhang X, Hu Y, Zhang Z, Wang R (2016) Dynamic properties of DNA-programmable nanoparticle crystallization. ACS Nano 10(8):7485-7492

94. Knorowski C, Burleigh S, Travesset A (2011) Dynamics and statics of DNA-programmable nanoparticle self-assembly and crystallization. Phys Rev Lett 106(21):215501

95. Knorowski C, Travesset A (2012) Dynamic of DNA-programmable nanoparticle crystallization: gelation, nucleation and topological defects. Soft Matter 8(48):12053-12059

96. Julin S, Korpi A, Nonappa, Shen B, Liljeström V, Ikkala O, Keller A, Linko V, Kostiainen MA (2019) DNA origami directed 3D nanoparticle superlattice via electrostatic assembly. Nanoscale 11(10):4546-4551

97. Sun W, Boulais E, Hakobyan Y, Wang WL, Guan A, Bathe M, Yin P (2014) Casting inorganic structures with DNA molds. Science 346(6210):1258361

98. Helmi S, Ziegler C, Kauert DJ, Seidel R (2014) Shape-controlled synthesis of gold nanostructures using DNA origami molds. Nano Lett 14(11):6693-6698

99. Ye J, Helmi S, Teske J, Seidel R (2019) Fabrication of metal nanostructures with programmable length and patterns using a modular DNA platform. Nano Lett 19(4):2707-2714

100. Liu X, Zhang F, Jing X, Pan M, Liu P, Li W, Zhu B, Li J, Chen H, Wang L, Lin J, Liu Y, Zhao D, Yan H, Fan C (2018) Complex silica composite nanomaterials templated with DNA origami. Nature 559(7715):593-598

101. Nguyen L, Döblinger M, Liedl T, Heuer-Jungemann A (2019) DNA origami templated silica growth by sol-gel chemistry. Angew Chem Int Ed 58(3):912-916 
102. Sonnichsen C, Reinhard BM, Liphardt J, Alivisatos APA (2005) Molecular ruler based on plasmon coupling of single gold and silver nanoparticles. Nat Biotechnol 23(6):741-745

103. Hentschel M, Saliba M, Vogelgesang R, Giessen H, Alivisatos AP, Liu N (2010) Transition from isolated to collective modes in plasmonic oligomers. Nano Lett 10(7):2721-2726

104. Halas NJ, Lal S, Chang WS, Link S, Nordlander P (2011) Plasmons in strongly coupled metallic nanostructures. Chem Rev 111(6):3913-3961

105. Zhang J, Constantinou PE, Micheel C, Alivisatos AP, Kiehl RA, Seeman NC (2006) Twodimensional nanoparticle arrays show the organizational power of robust DNA motifs. Nano Lett 6(7):1502-1504

106. Liu N, Liedl T (2018) DNA-assembled advanced plasmonic architectures. Chem Rev 118(6):3032-3053

107. Kuzyk A, Jungmann R, Acuna GP, Liu N (2018) DNA origami route for nanophotonics. ACS Photonics 5(4):1151-1163

108. Zhou C, Duan X, Liu N (2017) DNA-nanotechnology-enabled chiral plasmonics: from static to dynamic. Acc Chem Res 50(12):2906-2914

109. Siavashpouri M, Wachauf CH, Zakhary MJ, Praetorius F, Dietz H, Dogic Z (2017) Molecular engineering of chiral colloidal liquid crystals using DNA origami. Nat Mater 16(8):849-856

110. Shen X, Song C, Wang J, Shi D, Wang Z, Liu N, Ding B (2012) Rolling up gold nanoparticledressed DNA origami into three-dimensional plasmonic chiral nanostructures. J Am Chem Soc 134(1):146-149

111. Kuzyk A, Schreiber R, Fan Z, Pardatscher G, Roller E-M, Högele A, Simmel FC, Govorov AO, Liedl T (2012) DNA-based self-assembly of chiral plasmonic nanostructures with tailored optical response. Nature 483(7389):311-314

112. Lan X, Lu X, Shen C, Ke Y, Ni W, Wang Q (2015) Au nanorod helical superstructures with designed chirality. J Am Chem Soc 137(1):457-462

113. Urban MJ, Dutta PK, Wang P, Duan X, Shen X, Ding B, Ke Y, Liu N (2016) Plasmonic toroidal metamolecules assembled by DNA origami. J Am Chem Soc 138(17):5495-5498

114. Kuzyk A, Schreiber R, Zhang H, Govorov AO, Liedl T, Liu N (2014) Reconfigurable 3D plasmonic metamolecules. Nat Mater 13(9):862-866

115. Kuzyk A, Urban MJ, Idili A, Francesco R, Liu N (2017) Selective control of reconfigurable chiral plasmonic metamolecules. Sci. Adv 3(4):e1602803

116. Zhou C, Duan X, Liu N (2015) A plasmonic nanorod that walks on DNA origami. Nat Commun 6:8102

117. Lan X, Su Z, Zhou Y, Meyer T, Ke Y, Wang Q, Chiu W, Liu N, Zou S, Yan H, Liu Y (2017) Programmable supra-assembly of a DNA surface adapter for tunable chiral directional self-assembly of gold nanorods. Angew Chem Int Ed 56(46):14632-14636

118. Lan X, Liu T, Wang Z, Govorov AO, Yan H, Liu Y (2018) DNA-guided plasmonic helix with switchable chirality. J Am Chem Soc 140(37):11763-11770

Publisher's Note Springer Nature remains neutral with regard to jurisdictional claims in published maps and institutional affiliations. 